\title{
XLVI. Normal anomalies of the mean annual temperature variation
}

\section{Henryk Arctowski}

To cite this article: Henryk Arctowski (1917) XLVI. Normal anomalies of the mean annual temperature variation, Philosophical Magazine Series 6, 33:198, 487-495, DOI: $10.1080 / 14786440608635662$

To link to this article: http://dx.doi.org/10.1080/14786440608635662

册 Published online: 08 Apr 2009.

Submit your article to this journal $[\pi$

Џ Article views: 2

Q View related articles $₫$ 
in groups, in which the especial values are proportional to the atomic number. Thus the relation between the different groups, on the other hand, appears slightly more complicated.

The elements $\mathrm{H}-\mathrm{N}, \mathrm{O}-\mathrm{P}, \mathrm{S}-\mathrm{Cr}, \mathrm{Mn}$ and $\mathrm{Fe}$, Co and $\mathrm{Ni}$, $\mathrm{Cu}-\mathrm{Pd}$ seem to form fairly well-marked groups. A new group seems to begin at $\mathrm{Ag}$; the elements $\mathrm{Pt}-\mathrm{Pb}$ seem to belong to a special group, which also seems to be the case with the element $U$. In order to try to determine whether the atomic absorption coefficient even under other experimental conditions, may be arranged into the same groups, especially at a radiation more homogeneous than that used here, and also with rays of differing hardness, the experiments will be continued.

Stockholm, Nobel Institution for Physical Chemistry.

XLVI. Normal Anomalies of the Mean Annual Temperature Variation. By HeNryk ArCTOWski*.

THE curves representing annual variations of atmospheric 1 temperature are generally derived from monthly means. For many stations, belonging to different climates, these curves convey the impression of representing a cyclic variation, reflecting, with different amplitudes and more or less retardation, the seasonal changes of solar declination.

If, in the case of long series of observations, instead of monthly means, the averages for each day of the year are taken into consideration, the diagrams thus obtained display most remarkable anomalies. As typical examples I would refer to the curves of Konigsberg, Munich, Catania, and Valentia, published by Van Rijckevorsel $\dagger$, and to the curve derived from observations made in Melbourne, published by R. J.A. Barnard $\ddagger$. Because of its simplicity, the Melbourne curve may be taken as a demonstrative example of the problem in view.

From the highest mean temperature, observed in January, the means decrease more or less regularly till the middle of March ; then, suddenly, temperature increases about $2^{\circ} \mathrm{F}$. Another characteristic break occurs between June 15th and 20th. After the minimum of July the increase of temperature is again interrupted in September and also at the end of November.

* Communicated by the Author.

† Phil. Mag. ser. 5, vol. xlv. p. 459 (1898).

$\ddagger$ Phil. Mag. ser. 5, vol. 1. p. 408 (1900). 
The annual variation for Melbourne may therefore be represented by the following diagram (fig. 1).

Fig. 1.

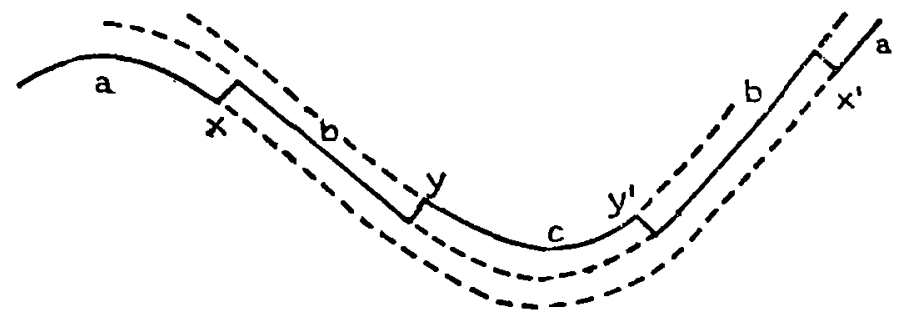

This diagram expresses graphically the opinion that the seasonal change of temperature in Melbourne is not what it should be; that at given dates of the year $\left(X, Y, Y^{\prime}, X^{\prime}\right)$ the natural course of temperature, due to local conditions, is interrupted, just as if the station had been shifted into another climate, similar, but colder than it ought to be during the summer, and warmer than it ought to be during the winter.

The annual variation proceeds by steps. The steps of ascen $\mathrm{l}$, occurring while the temperature is decreasing, correspond to similar steps of descent observed during the other half of the year.

Each successive stage marks the passage from one phase to another.

In the preceding example the annual variation is composed of three phases.

This opinion seems never to have been advanced, and it is astonishing to notice that even the fact of the existence of steps during the autumn, corresponding to the steps of the spring, has, so far as I know, attracted practically no attention; though the frequently recurring temperature anomalies for given dates, in May and June, have been very extensively studied.

Researches of particular interest concerning these anomalies are those of G. Hellmann*, W. v. Bezold †, Ch. Dufour $\ddagger$,

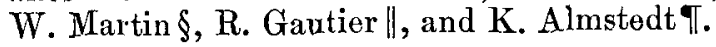

* Ann. d. Phys. u. Chem. vol. clix. p. 36 (1876).

† Abh. math.-phys. Kl. K. Bay. Akad. Wiss. vol. xiv. II. p. 69 (1883).

1 Bull. Soc. Vaud. Sc. ser. 3, vol. xxix. p.316 (1893).

\$ Abh. K. Preass. Met. Inst. vol, ii. No.3 (1902).

II Arch. Sc. Phys. et Nat. ser. 4, vol. xxxi. p. 497 (1911).

१ी Meteor. Zeit. vol. xxxi. p. 426 (1914). 
The principal results gained by these authors may be summarized as follows:-

(1) The temperature depressions are not strictly bound to given dates. Their occurrence varies slightly from year to year, but on the average, in Central Europe, the lith15th of May and the 4th-8th of June show a well-pronounced deficiency of temperature.

(2) In all cases, of given years, the comparison of the records has shown a progressive displacement of the wave of cold.

(3) A characteristic distribution of atmospheric pressure over Europe is noticeable. On the ocean a high-pressure area, extending an anticyclonic tongue eastward, moves slowly from the centre of action of the Azores northward.

(4) The resultants of the observed wind directions change radically.

(5) Considering a long series of observations, groups of years may be distinguished for which the temperature depressions of May and June are well pronounced, while in other groups of years they occur only occasionally.

This fact applies at least to the Paris ${ }^{*}$ and Geneva $\dagger$ observations.

The marked departure of temperature conditions of given dates, from the steady seasonal advance, may receive three different interpretations which are illustrated by the following diagram (fig. 2).

Curve " $\mathrm{A}$ " expresses the hypothesis that temperature is below the normal for given dates " $K$," and that " $a$ " " is the continuation of curve "a." This represents the very generally admitted hypothesis.

Curve " B " represents the anomaly " $p$ " as being due to such more or less sudden change in the distribution of the isotherms that " $b$ " belongs to a curve identical with " $a$," but shifted downwards.

Curve " $\mathrm{C}$ "presupposes a radical modification of the annual variation. At " $q$ " the curve " $b$ " is supposed to have a greater amplitude than " $a$ "; at " $r$ " the curve " $c$ " is supposed to have a smaller amplitude than "b."

A careful examination of the available temperature curves

* E. Renou, Annales Bur. Centr. Mét. France, vol. i. p. B. 195 (1887).

+ R. Gautier et H. Duaime, Arch. Sc. Phys. ser. 4, vol. xष. p. 545 (1903).

Phil. Mag. S.6. Vol. 33. No. 198. June 1917. 2 M 
shows that curve "A" may be discarded. On the contrary, curves " $\mathrm{B}$ " and " $\mathrm{C}$ " must both be taken into consideration.

Fig. 2.

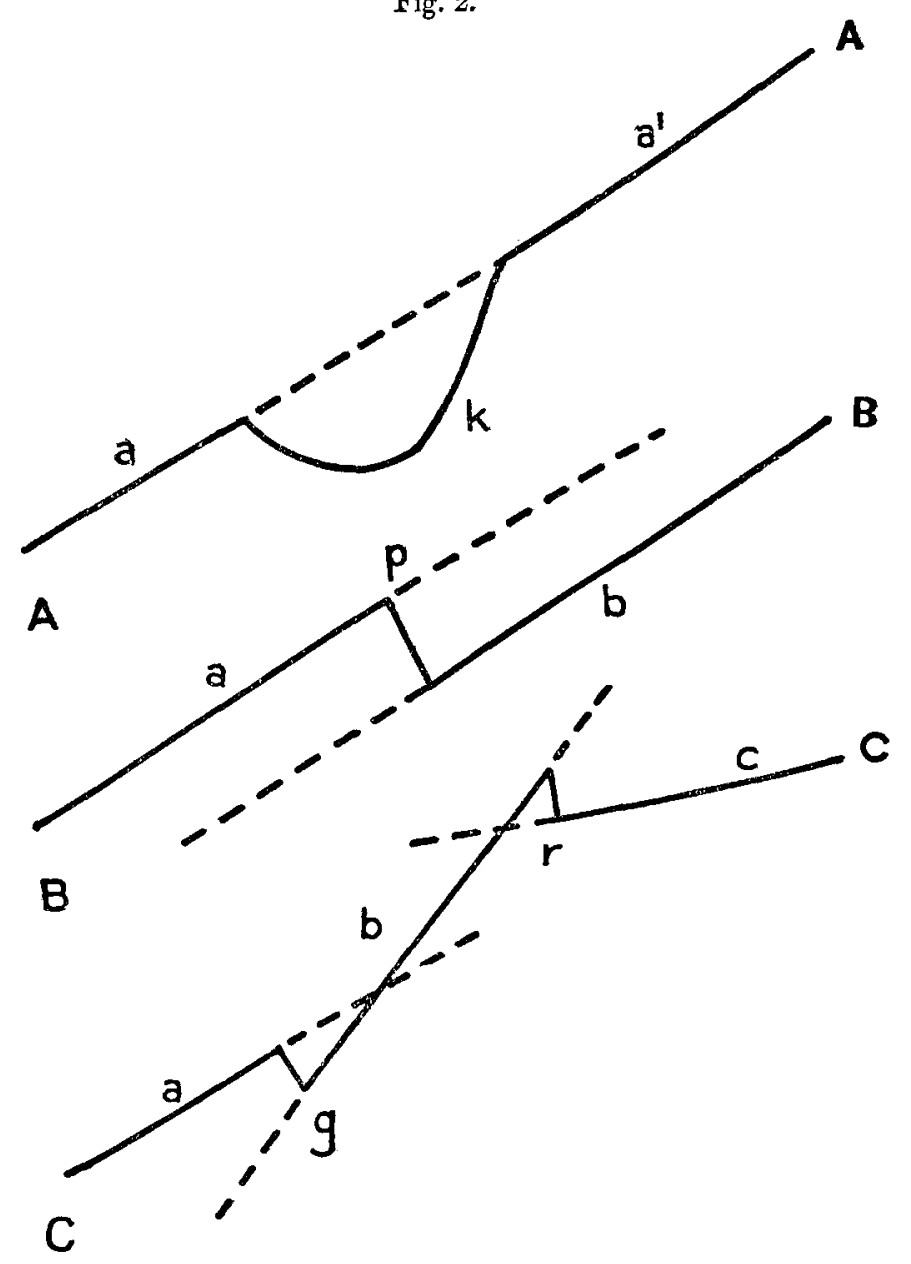

As a typical example I will cite the temperature curve for Warsaw.

The utilized daily means are those of the years 1826-1880*.

- Jan Kowalczyk, Pam. Fizjogr., Warsaw, 1881.; 
The following diagram (fig. 3) gives an interpretation of the detailed curve.

Fig. 3.

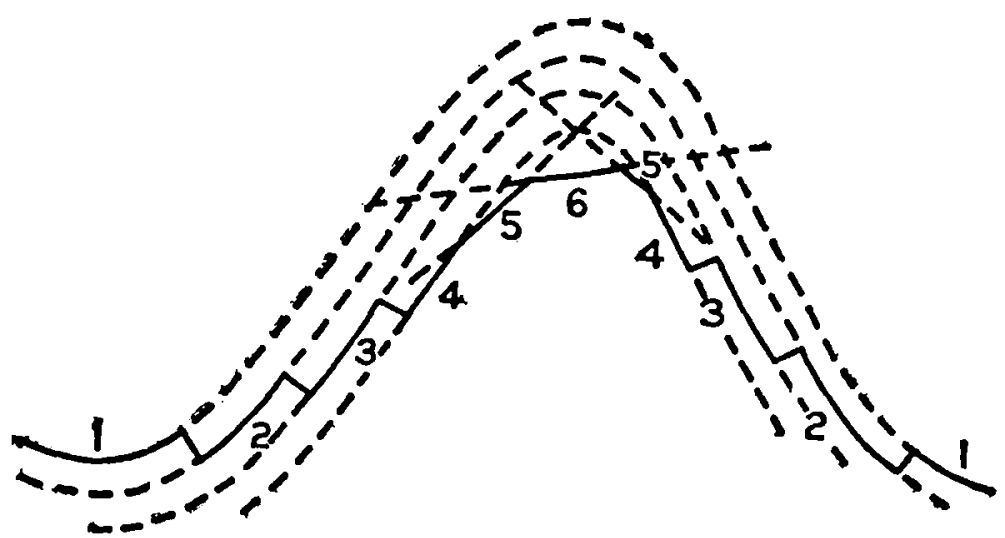

The variation is composed of phases $1,2,3$, and 4 belonging to four concordant curves. The steps occur approximately at the following dates: Jan. 25, March 9, April 22, Oct. 2, Nov. 29, and Dec. 16.

Then, during the summer, on the contrary, from June 9th till July 28 th, we have practically a straight line of mean temperatures increasing from $17^{\circ} \cdot 6$ to $19^{\circ} \cdot 3 \mathrm{C}$. This line 6 is evidently discordant : it cuts all the others. The summer maximum is $3^{\circ}$ below the maximum which would be observed if curve 4 were fully developed. The summer temperature may therefore be considered abnormally low. Now, between 6 and 4 we observe the fragments of a curve 5 extending from May 22nd to June 8th and July 29th to Aug. 26th. This curve intersects all the others : its amplitude is evidently much smaller than the amplitude of curves 1-4.

Although the temperature curve for Warsaw may be considered a most typical example of these normal anomalies of the annual temperature variation, the breaks being too well accentuated to be ascribed to chance circumstances, it is useful to cite a few other examples in order to show how, gradually, we pass from one type of variation to another.

Hellmann has published * a detailed curve of the daily means derived from the observations made in Berlin during the years 1848-1907. Referring to the diagram for Warsaw (fig. 3), the Berlin curve displays the fragments $1-4,5$ is missing, and 6 is a well-developed curve extending from June 13th to Sept. 21st, with a maximum on July 22nd.

* Preuss. Met. Inst., Abh. vol. iii. No. 6, Berlin, 1910. 
From March 13th to April 7th the increase in temperature is abnormally rapid, so that 3 is discordant with 2 and 4. The drop of temperature between 4 and 6 (June 6-11) is $1^{\circ} .5 \mathrm{C}$. This is perhaps the most characteristic feature of the curve. Besides, 4 and 6 are discordant. Phase 6 has a smaller amplitude than 4 .

Evidently if many curves were available it would be interesting to follow the progressive change from station to station. That these anomalies do not occur simultaneously at different stations but gradually propagate from place to place is a well-established fact, at least for some of the temperature depressions of the spring. 'The curves for Arcachon, Greenwich, Berlin, Lemberg, Penza, and Wologda, published by Almstedt*, may serve as examples.

Without adopting in their integrity the ideas expressed long ago by Dove $\dagger$, let us suppose now that the temperature curve for Melbourne, or the curve for Warsaw, or the curves for other places, exhibiting similar anomalies, express the result of an antagonism between maritime and continental climates, respectively characterized by a very small and a very large annual amplitude.

On the ocean, west of the coast of France, the difference between the mean temperatures of the warmest and the coldest day of the year is certainly less than $10^{\circ} \mathrm{C}$. In Paris it is $18^{\circ} .7^{\mathrm{C}}$., in Warsaw $24^{\circ} \cdot 7$, in Barnaoul it is $41^{\circ} \cdot 8$, and the observations of Nertchinsk give $49^{\circ} \cdot 9 \mathrm{C}$. I have traced the curves for Barnaoul (means of the observations made from 1838-1882), and Nertchinsk (1839-1881) $\ddagger$, and have found, to my great astonishment, that from March 15 th to November 1st these two curves are practically identical, whereas during the winter months they differ very greatly one from the other. The winter in Nertchinsk is very much colder than in Barnaoul. The temperatures are :-

$\begin{array}{lrrcc} & & & \text { Barnaoul. } & \text { Nertehinsk. } \\ \text { October } & 31 & \ldots . . & -3^{\circ} \cdot 6 & -7^{\circ} \cdot 2 \\ \text { January } & 2 & \ldots \ldots & -18^{\circ} .3 & -30^{\circ} .7 \\ \text { March } & 15 & \ldots \ldots & -10^{\circ .8} & -13^{\circ} .1\end{array}$

The maxima of the summer are :-

Barnaoul............. $20^{\mathrm{c}} \cdot 2$ on July the 4 th.

Nertchinsk.......... $19^{\circ} \cdot 2 \quad, \quad, 12$ th.

* Loc. cit.

$\dagger$ Abh. K. Akad. Wiss. Berlin, p. 121 (1856).

$\ddagger$ Repert.f. Meteor. Suppl. 3, St. Petersbourg, 1886. 
The temperature curve of Barnaoul belongs therefore to two climates. During the months of April to October it belongs to the excessive continental climate of Nertchinsk, while in the winter it belongs ta a less continental climate.

The following diagram (ng. 1) vives the daily means of temporature in Nortchinsk for the months of May and June.

Fig. 4.

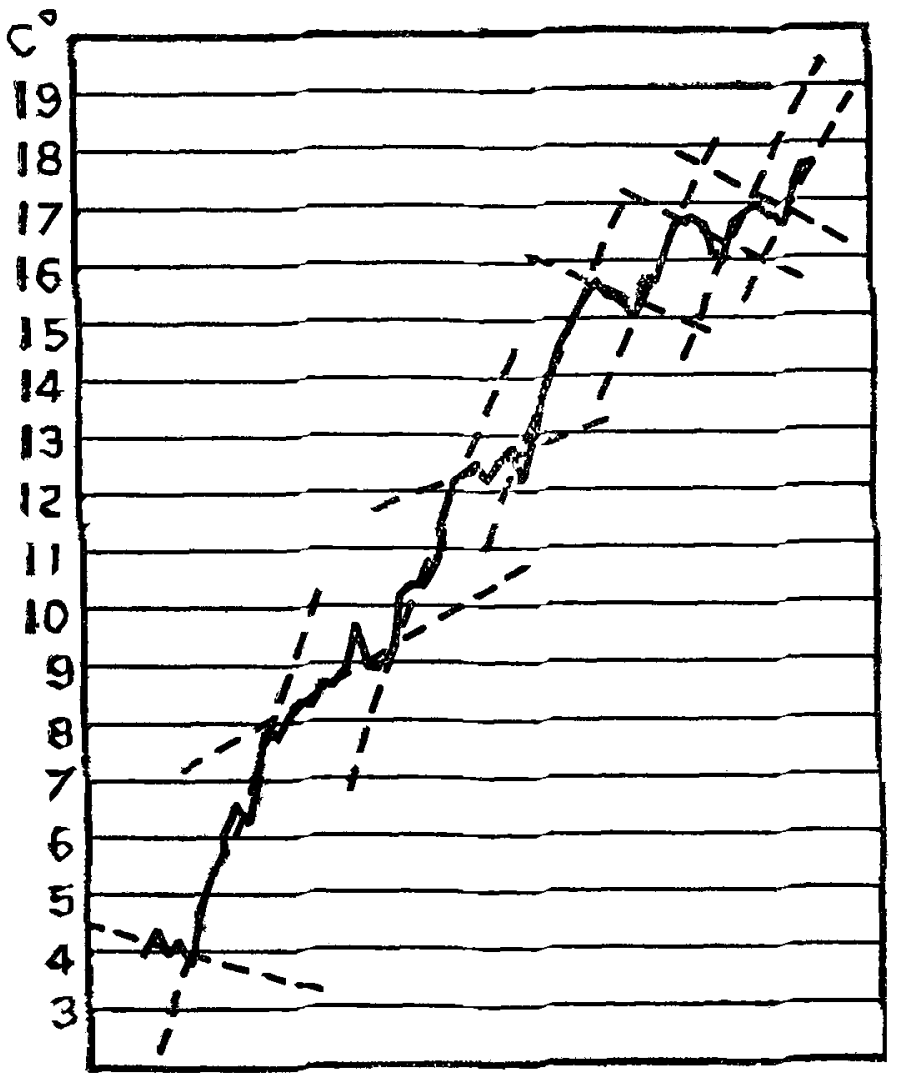

The diagram shows that the increase of temperature procoeds by steps. Going up the curve slides down here and there and goes up again. The total depression of the yearly auplitude, due to these steps, may bo estimated at $17^{\circ}$. Admitting this estimate and supposing that curve of 
$67^{\circ}(=50+17)$ amplitude would represent the variation corresponding to the coefficient of perfect atmospheric transparency* at the latitude of Nertchinsk, the lowest temperature of January must be considered $6^{\circ} \cdot 5$ too high, and the highest July temperature $11^{\circ} \cdot 5$ too low, since the extreme daily mean temperatures should be $-37^{\circ}$ and $+30^{\circ}$.

Thus it may be that, in this case, the decrease in amplitude is in close connexion with the annual variation of atmospheric moisture. During the summer months, the greater amount of aqueous vapour diminishes the coefficient of atmospheric (thermal) transparency very much more than during the winter months, and so it is evident that the summer temperatures differ more from what they should be than the temperatures observed during the winter.

This leads to the question whether the steps of the Nertchinsk temperature curve, and perhaps also the steps of the curves of several other stations, are not partially due to a rhythmical transport of atmospheric moisture.

In the ascending part of the curve of Barnaoul the depressions following the crests generally precede by 2 to 4 days the corresponding details of the curve of Nertchinsk. The inflexions of the isotherms characteristic for these changes progress therefore across Siberia from the W. towards the E.

But, as a result of the International Balloon ascents of May 13th, 1897, Hergesell has shown that the typical decrease of temperature observed then in Central Europe was very much more accentuated at high altitudes than it was near the ground $\dagger$. Similar observations have been made since. In consequence, the inflexion of the isotherms must be more pronounced at an altitude of $10,000 \mathrm{~m}$. than it is at the surface of the earth's crust. After each step of the ascending temperature curve the entire air-mass above the station where the step has been observed is changed. The work of the progressive heating of the ground by solar radiation and the heating of the air-mass ahove by convection currents, must, to a certain extent, be begun anew, and probably under different conditions.

Evidently, to reach a definite conclusion it would be necessary to study the records of individual years and the weather maps as well. But the real difficulty, and at the same time the great interest of the study of these normal

* A. Angot, Ann. Bur. Centr. Met. France, vol. i. p. B. 121 (1883).

$\dagger$ Meteor. Zeit. vol. xvii. p. 1 (1900). 
anomalies of the mean annual temperature variation, resides in the fact that we have to deal with a phenomenon showing intimate relationship between very far distant stations.

On the opposite side of the world, in Baltimore*, the temperature crests of February 22nd, March 10th, April 14th, and May 10th, there observed, belong also to the curves of Barnaoul and Nertchinsk. In Barnaoul they occur : February 18, March 9, April 21, and May 10. In Nertchinsk, February 22, March 12, April 20 (and May 12).

Already Dove $\dagger$ noticed the fact that the anomaly occurring during the month of May is noticeable in the records collected in Arctic America and Greenland. On the other hand, according to R. C. Mossman $\ddagger$, the cold period of May is well pronounced in Argentina and Chile, north of $40^{\circ} \mathrm{S}$. lat., and it was also observed at the winter quarters of the 'Discovery' in 1902 and 1903, at Cape Adare in 1899, at the South Orkneys during all the years of observation from 1903 to 1908 , with the exception of 1906 .

Mossman remarks that thus the temperature anomaly of May is a bipolar phenomenon, and he adds that the curve of mean atmospheric pressure at the South Orkneys, for each day of the year, bears a close resemblance to that of Edinburgh.

Forcibly therefore we reach the conclusion that in a comparative study of the anomalies of the annual temperature variation, Teisserene de Bort's conception of the great centres of action of atmospheric circulation will find an extensive application ; because, although at present it would be premature to try to explain why it is that some changes of phase may occur simultaneously in Arctic and Antarctic regions, or in North America and Siberia, it seems impossible to conceive such correlations without supposing some relationship with the exchange of pressure between the seasonal and permanent centres of action.

New York City, November 2, 1916.

* O. L. Fassig, 'The Climate and Weather of Baltimore,' pl. 3, Baltimore, 1907.

+ Loc. cit.

t Symon's Met. Mag. vol. xlir. p. 1 (1909). 